\title{
The method of translation additive and multiplicative error in the instrumental component of the measurement uncertainty
}

\author{
Olexander M. Vasilevskyi*a, Volodymyr Y. Kucheruk ${ }^{\mathrm{a}}$, Volodymyr V. Bogachuk ${ }^{\mathrm{a}}$, Konrad \\ Gromaszek $^{\mathrm{b}}$, Waldemar Wójcik ${ }^{\mathrm{b}}$, Saule Smailova ${ }^{\mathrm{c}}$, Nursanat Askarova ${ }^{\mathrm{b}}$ \\ ${ }^{a}$ Department of Metrology and Industrial Automation, Vinnytsya National Technical University, \\ $95 \mathrm{Khmelnitskoye} \mathrm{Shose,} \mathrm{Vinnitsya,} \mathrm{21021,} \mathrm{Ukraine;}{ }^{b}$ Institute of Electronics and Information \\ Technology, Lublin University of Technology, ul. Nadbystrzycka 38A, 20-618 Lublin, Poland; \\ ${ }^{c}$ D.Serikbayev East Kazakhstan State Technical University, 070004, Ust-Kamenogorsk City, 69 \\ A.K. Protozanov Street, Kazakhstan.
}

\begin{abstract}
The paper proposes a method of conversion additive and multiplicative errors, mathematical models are obtained by a Taylor expansion of the transformation equations used measuring instruments in the instrumental component of the measurement uncertainty.
\end{abstract}

Keywords: transformation equation, measuring means, additive errors, multiplicative errors, uncertainty

\section{INTRODUCTION}

This research was conducted into the basic metrological characteristics displayed when developing new designs of measurement means for the evaluation of physical quantities, which is seen to be a crucial issue in science, the solution helping to ensure the uniformity of measurements and the identification of core and additional errors (uncertainties) in the measurement of a given type of measurement means.

As has been demonstrated in the relevant literature [see bibliography ${ }^{1-5}$ ], the basic characteristics of measurement means include conversion equations, static characteristics, sensitivity, additive and multiplicative errors, the measurement range, and the basic and additional errors in the Measurement Means (MM). These characteristics are sufficient to establish standards for the accuracy of the MM. This requires that the mathematical tools used in research study of the MM in static mode enable us to easily obtain functions of the metrological characteristics enumerated above. The difficulty is that the equations describing measurement conversion describe different physical processes for different MMs, which relate to a variety of disciplines and are functions of numerous variables. It would be valuable to produce a generalised method of research, independent of the physical phenomena underlying the design of MMs. This research aims to achieve this, by appraising a series of derived conversion equations using the Taylor's Series method to study static metrological characteristics by mathematical means ${ }^{1-5}$.

As a result of the above, the aim of this paper is to obtain mathematical models of basic static metrological characteristics, enabling us to explore and analyse the characteristics of their change and synthesise MM for torque using predetermined standardised metrological characteristics and to develop methods of recalculating additive and multiplicative components in MM errors in an instrumental component of the measurement uncertainty.

\section{MODEL EQUATIONS FOR TORQUE MEASUREMENT MEANS}

Using the analytical expression of the conversion function of a $\mathrm{MM}$ of the torque of electric motors in static mode and the standard equation for conversion by an analogue-to-digital converter (ADC), we obtain this equation for the conversion of a torque MM, which we may use to obtain basic metrological characteristics ${ }^{6-8}$

$$
N_{M y}=0,25 U_{p} 2^{m} g^{-1} 1^{-1} R^{-1} S_{C}^{-1} U_{o}^{-1}\left(M_{P}-M_{M S}+K 1\left(S+\left(M_{P}-M_{M S}\right) \frac{T_{s} p}{i \eta J \omega_{r}}\right)\left(\gamma-\frac{T_{s} p}{J \omega_{r}}\right)^{-1} J^{-1} \omega^{-2}\right),
$$

*o.vasilevskyi@gmail.com; phone +380633699505

Photonics Applications in Astronomy, Communications, Industry, and High-Energy Physics Experiments 2016, edited by Ryszard S. Romaniuk, Proc. of SPIE Vol. 10031, 1003127 · (C) 2016 SPIE

CCC code: $0277-786 X / 16 / \$ 18 \cdot$ doi: $10.1117 / 12.2249195$ 
where $U_{p}$ is the ADC supply voltage; $U_{O}$ is the ADC reference voltage; $m$ is the ADC digital capacity; $g$ is the acceleration of gravity; 1 is the length of the measurement arm; $R$ is resistance value of the tensoresistive bridge; $\mathrm{S}_{\mathrm{C}}$ is the value of the sensitivity of the effort sensor; $\omega$ is the free natural frequency (undamped) of the fluctuations of the transformer; $\mathrm{K} 1$ is the value of the coefficient of the conversion of the tensoresistive transformer; $\mathrm{S}$ is the slip; $\mathrm{J}$ is the moment of inertia of the moving part of the electric motor (EM); $p$ is the number of pole pairs of the EM; $i$ is the transmission value of the reductor; $\eta$ is the efficiency coefficient of the reductor; $\omega_{\mathrm{r}}$ is the angular speed of the EM rotor; $\mathrm{M}_{\mathrm{MS}}$ is the moment of eccentricity of the clutch coupling; $\mathrm{T}_{\mathrm{S}}$ is the electromagnetic time constant of the stator; $\gamma$ is the value of the coefficient of the slope of the slip characteristics; $\mathrm{M}_{\mathrm{P}}$ is the torque of the electric motor (measured value).

\section{THE METROLOGICAL CHARACTERISTICS OF MEANS OF MEASURING}

Under the working conditions of the MM, the torque provides functional conversion of the informative (useful) parameter MP in the source code NMy. In addition to the informative signal, it is also influenced by impact values which include all the other parameters that have a direct relationship with the original value and causing uninformative (stray) components of the conversion. Analysis of the derived conversion equation (1) demonstrates that the process of the conversion of informative parameter in the output signal is influenced by a large number of parameters (impact values). But due to the fact that almost all the values are unchanged, and one of the most important parameters when testing the EM in addition is the torque is the moment of inertia, we will explore the impact of the moment of inertia as an impact value on the informative parameter.

To obtain analytical dependences of the basic static metrological characteristics of the MM of the torque we may use Taylor's Series with our conversion equation (1) to obtain

$$
\begin{aligned}
\mathrm{N}_{\mathrm{My}}=\mathrm{N}_{\mathrm{My} 0} & \left.+\frac{\partial \mathrm{N}_{\mathrm{My}}}{\partial \mathrm{M}_{\mathrm{P}}}\right]_{0} \mathrm{M}_{\mathrm{P}}+\frac{1}{2 !}\left[\frac{\partial^{2} \mathrm{~N}_{\mathrm{My}}}{\partial \mathrm{M}_{\mathrm{P}}^{2}}\right]_{0} \mathrm{M}_{\mathrm{P}}^{2}+\frac{1}{3 !}\left[\frac{\partial^{3} \mathrm{~N}_{\mathrm{My}}}{\partial \mathrm{M}_{\mathrm{P}}{ }^{3}}\right]_{0} \mathrm{M}_{\mathrm{P}}^{3}+ \\
& +\ldots+\left[\frac{\partial^{2} \mathrm{~N}_{\mathrm{My}}}{\partial \mathrm{M}_{\mathrm{P}} \partial \mathrm{J}}\right]_{0} \mathrm{M}_{\mathrm{P}} \Delta \mathrm{J}+\left[\frac{\partial \mathrm{N}_{\mathrm{My}}}{\partial]_{0}} \Delta \mathrm{J}+\frac{1}{2 !}\left[\frac{\partial^{2} \mathrm{~N}_{\mathrm{My}}}{\partial \mathrm{J}^{2}}\right]_{0} \Delta \mathrm{J}^{2}+\ldots .\right.
\end{aligned}
$$

The analytical expression of the sensitivity of the torque MM has the form

$$
\mathrm{S}_{\mathrm{M}_{\mathrm{P}}}=\frac{\partial \mathrm{N}_{\mathrm{My}}}{\partial \mathrm{M}_{\mathrm{P}}}=\frac{\mathrm{U}_{\mathrm{p}} 2^{\mathrm{n}}\left(\frac{\mathrm{K} 1 \mathrm{~T}_{\mathrm{s}} \mathrm{p}}{i \eta \mathrm{J}^{2} \omega_{\mathrm{r}}\left(\gamma-\frac{\mathrm{T}_{\mathrm{s}} \mathrm{p}}{\mathrm{J} \omega_{\mathrm{r}}}\right) \omega^{2}}+1\right)}{4 \mathrm{glRS} \mathrm{C}_{\mathrm{o}}} .
$$

Changes in sensitivity across the range of conversion of the informative parameter MP is a derivative of the second order

equation of the conversion (1) where $\mathrm{S}_{\mathrm{M}_{\mathrm{P}}}^{\prime}=\frac{\partial^{2} \mathrm{~N}_{\mathrm{My}}}{2 \partial \mathrm{M}_{\mathrm{P}}^{2}}$ in this case is zero.

The coefficients of the influence of the impact value i.e the moment of inertia $\mathrm{J}$ on the output parameter of the measurement means of the torque, may be described by analytical expressions such as: 


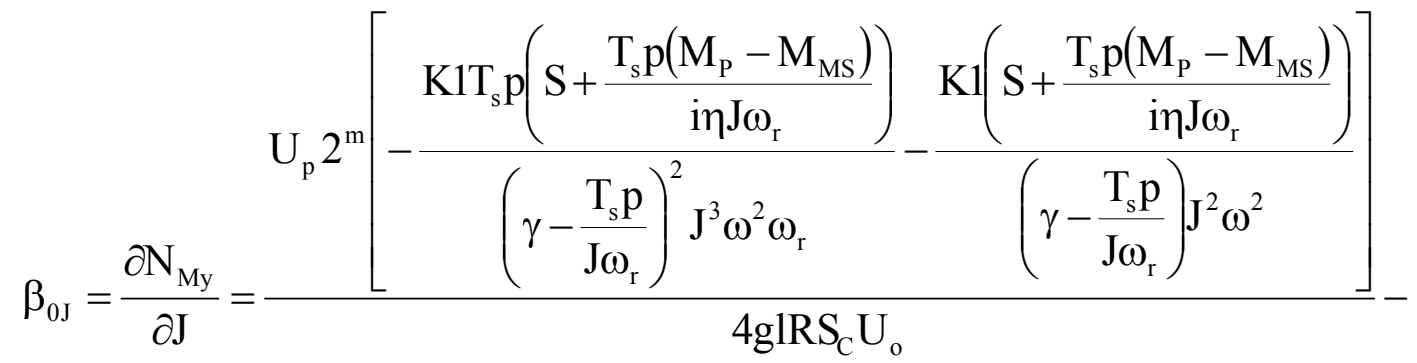

$$
\begin{aligned}
& -\frac{U_{p} 2^{m} \operatorname{K}_{1 T} p\left(M_{P}-M_{M S}\right)}{4 g 1 R S_{C} U_{o} i \eta\left(\gamma-\frac{T_{s} p}{J \omega_{r}}\right) J^{3} \omega^{2} \omega_{r}} ; \\
& \beta_{0 J}^{\prime}=\frac{\partial^{2} N_{M y}}{2 \partial J^{2}}=\frac{U_{p} 2^{m}\left[\frac{2 K 1 T_{s}^{2} p^{2}\left(S+\frac{T_{s} p\left(M_{P}-M_{M S}\right)}{i \eta J \omega_{r}}\right)}{\left(\gamma-\frac{T_{s} p}{J \omega_{r}}\right)^{3} J^{5} \omega^{2} \omega_{r}^{2}}+\frac{4 K 1 T_{s} p\left(S+\frac{T_{s} p\left(M_{P}-M_{M S}\right)}{i \eta J \omega_{r}}\right)}{8 g l R S_{C} U_{o}}\right]}{\left(\gamma-\frac{T_{s} p}{J \omega_{r}}\right)^{2} J^{4} \omega^{2} \omega_{r}}+
\end{aligned}
$$

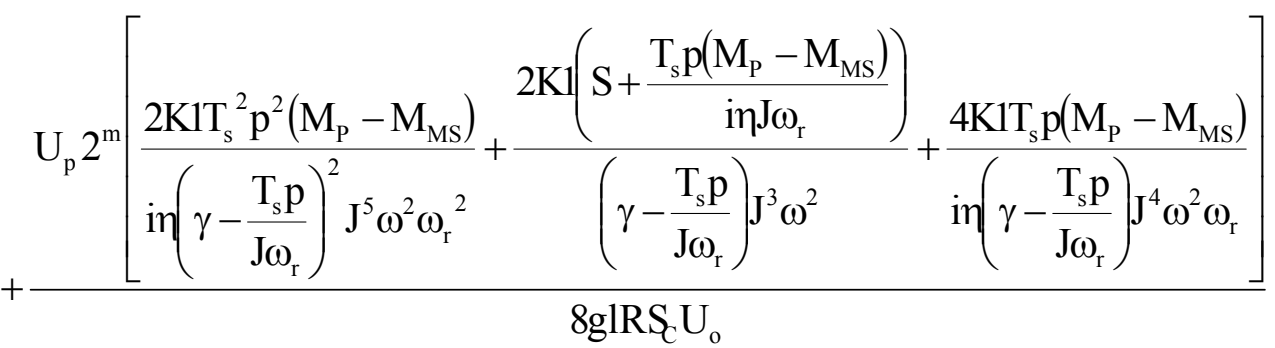

The coefficient of joint influence of the informative parameter and the impact value -that is the moment of inertia $\mathrm{J}$ on the nominal sensitivity SMp of the torque MM, may be described by an analytical expression with the form

$$
\alpha_{0 J}=\frac{\partial^{2} \mathrm{~N}_{\mathrm{My}}}{\partial \mathrm{M}_{\mathrm{P}} \partial \mathrm{J}}=\frac{\mathrm{U}_{\mathrm{p}} 2^{\mathrm{m}}\left(-\frac{\mathrm{K} 1 \mathrm{~T}_{\mathrm{s}}^{2} \mathrm{p}^{2}}{\left(\gamma-\frac{\mathrm{T}_{\mathrm{s}} \mathrm{p}}{\mathrm{J} \omega_{\mathrm{r}}}\right)^{2} \mathrm{~J}^{4} \omega^{2} \mathrm{i} \eta \omega_{\mathrm{r}}{ }^{2}}-\frac{2 \mathrm{~K} 1 \mathrm{~T}_{\mathrm{s}} \mathrm{p}}{\left(\gamma-\frac{\mathrm{T}_{\mathrm{s}} \mathrm{p}}{\mathrm{J} \omega_{\mathrm{r}}}\right) \mathrm{J}^{3} \omega^{2} i \eta \omega_{\mathrm{r}}}\right)}{4 \mathrm{glRS} \mathrm{C}_{\mathrm{o}}} .
$$

The analytical expression of the nominal function of the conversion of the torque MM taking into account equation (3) may now be stated in the form:

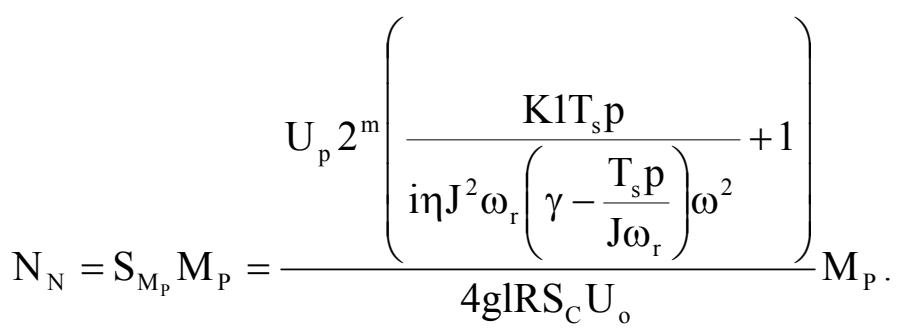


The analytical expression which describes the absolute multiplicative error of the torque MM $\Delta N_{M J}$ under the condition of the change of the moment of inertia $\mathrm{J}$ (as an impact value) on the value where $\Delta J=J-J_{N}$, now takes the form:

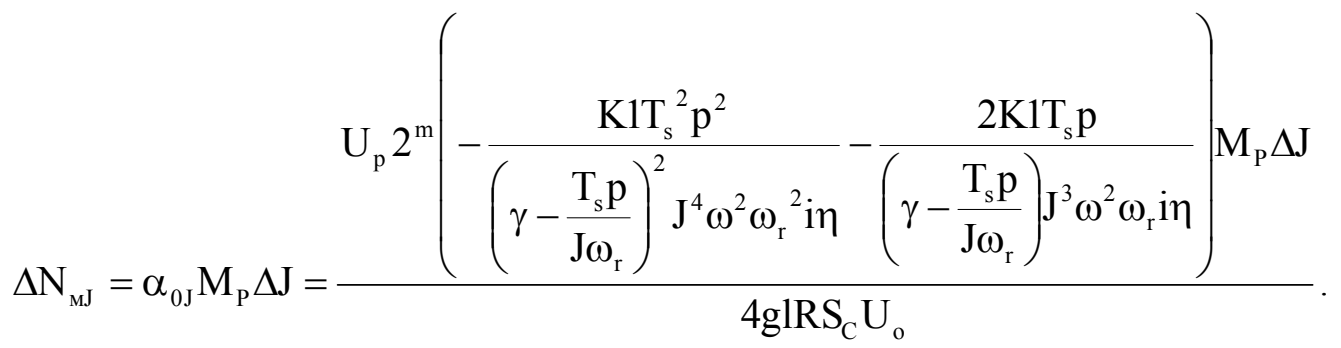

The analytical expression describing the absolute additive error of the torque MM $\Delta N_{a J}$ under the conditions where the change in the moment of inertia $\mathrm{J}$ (as an impact value) on the value of $\Delta J$, may now be expressed as

$$
\begin{gathered}
\Delta \mathrm{N}_{\mathrm{aJ}}=\beta_{0 \mathrm{~J}}\left(\mathrm{~J}-\mathrm{J}_{\mathrm{N}}\right)+\beta_{0 \mathrm{~J}}^{\prime}\left(\mathrm{J}-\mathrm{J}_{\mathrm{N}}\right)^{2}= \\
=-\frac{\mathrm{U}_{\mathrm{p}} 2^{\mathrm{m}} \mathrm{K} 1 \mathrm{Si \eta} \mathrm{J}^{3} \omega_{\mathrm{r}} \gamma\left(\omega_{\mathrm{r}}^{2} \gamma \mathrm{J}_{\mathrm{N}}-\mathrm{T}_{\mathrm{s}} \mathrm{p}\right) \Delta \mathrm{J}}{4 \mathrm{glRS} \mathrm{C}_{\mathrm{C}} \mathrm{U}_{\mathrm{o}}\left(\gamma \mathrm{J} \omega_{\mathrm{r}}-\mathrm{T}_{\mathrm{s}} \mathrm{p}\right)^{3} \mathrm{~J}^{3} \omega^{2} \mathrm{i} \eta}+ \\
+\mathrm{U}_{\mathrm{p}} 2^{\mathrm{m}} \mathrm{K} 1 \Delta \mathrm{J} \frac{\left(\mathrm{M}_{\mathrm{P}}-\mathrm{M}_{\mathrm{MS}}\right)\left(\mathrm{T}_{\mathrm{s}}^{3} \mathrm{p}^{3} \mathrm{~J}_{\mathrm{N}}-\mathrm{T}_{\mathrm{s}} \mathrm{p} \gamma^{2} \mathrm{~J}^{3} \omega_{\mathrm{r}}{ }^{2}-3 \mathrm{~T}_{\mathrm{s}}^{2} \mathrm{p}^{2} \mathrm{~J}_{\mathrm{N}} \gamma \mathrm{J} \omega_{\mathrm{r}}+3 \mathrm{~T}_{\mathrm{s}} \mathrm{pJ} \mathrm{J}_{\mathrm{N}} \gamma^{2} \mathrm{~J}^{2} \omega_{\mathrm{r}}^{2}\right)}{4 \mathrm{~g} 1 \mathrm{RS} \mathrm{S}_{\mathrm{C}} \mathrm{U}_{\mathrm{o}}\left(\gamma \mathrm{J} \omega_{\mathrm{r}}-\mathrm{T}_{\mathrm{s}} \mathrm{p}\right)^{3} \mathrm{~J}^{3} \omega^{2} \mathrm{i} \eta} .
\end{gathered}
$$

The characteristics of change in the obtained metrological models of static characteristics models (1), (3) - (9), of the torque measurement means at nominal values for the impact values, are shown in Figures 1 - 7.

As may be seen in Figure 1, the static characteristics of conversion equation (1) of the torque MM are linear over the entire range of measurement. The sensitivity of the MM (Figure 2) is constant, and therefore the scale of such a MM is even.

Figure 1. Static characteristics of the torque MM.

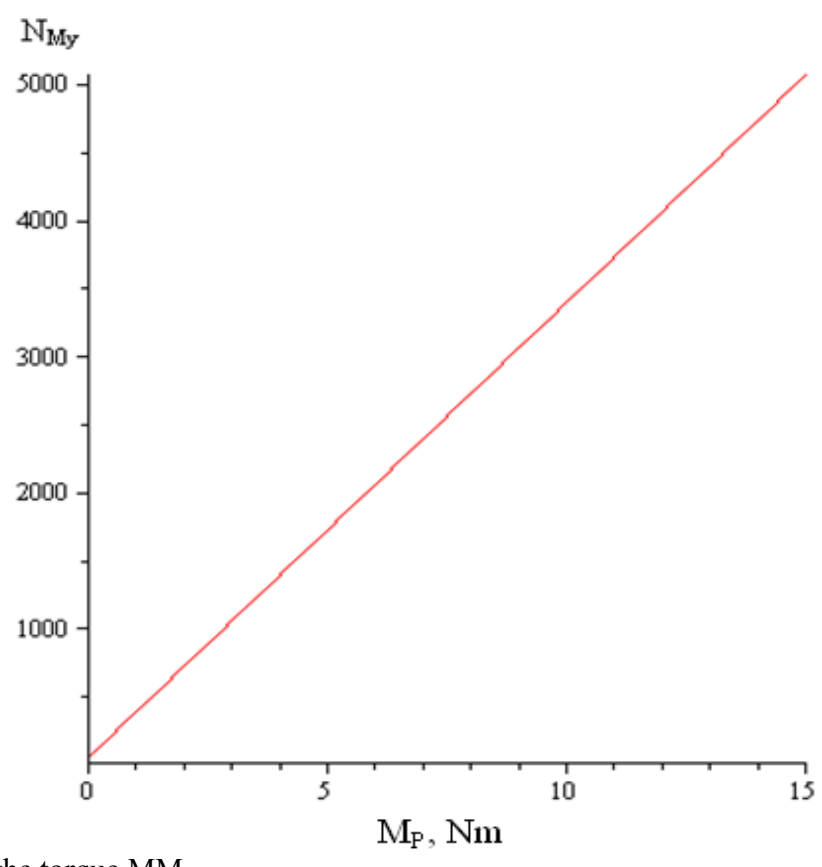


It may be seen in Figure 4 that the absolute multiplicative error of the torque MM under the conditions of deviation of the impact value $J$ will acquire the highest values when measuring the torque at the upper limits of the measuring range. The range of fluctuation in the multiplicative error under the conditions of deviation of the impact value $J$, from its nominal value, is 500 denary pulses at the value of the maximum output code of 5000 pulses, that equals $10 \%$. Therefore, it is feasible that the nominal value of the moment of inertia of the electric motor when undertaking measurements of the torque of the electric motor may take into account the above nominal value when calculating the torque in a digital measurement transformer of the torque MM.

In terms of deviation of the impact value $\mathrm{J}$ (moment of inertia of the electric motor) from its nominal value by the amount $\Delta \mathrm{J}$, the value of the absolute additive error of the torque MM increases when the value of the moment of inertia of the electric motor is more than $0,0014 \mathrm{Nm} 2$ (Figure 8). And as the additive error is independent of the measured value, the determination of its value is problematic.

Characteristics of the change of the nominal function of the conversion (Figure 3) of the torque MM are analogous to the theoretical static characteristics described by analytical expression (1). The characteristics which demonstrate the difference between theoretical characteristics of the torque MM (1) and the nominal function of the conversion (7) are shown in Figure 9.

Figure 2. MM sensitivity.

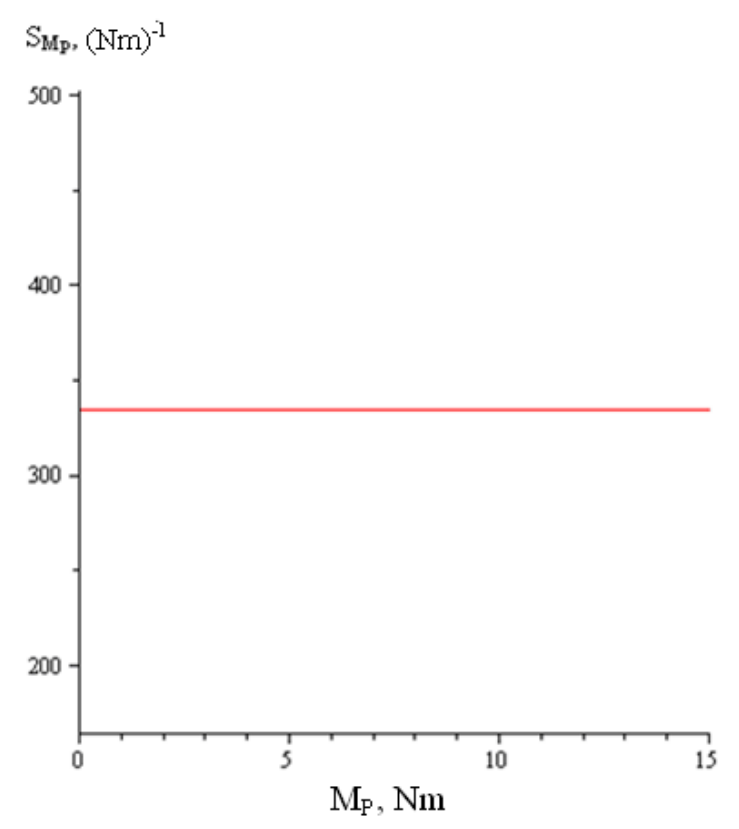

As may be seen in Figure 9, the discrepancy in the values between the theoretical characteristics and the characteristics of the change in the nominal function of conversion across the entire range of torque measurement differ only by a constant absolute value of the decimal base $\Delta \mathrm{NMp}$ not exceeding 57 pulses. Taking into account that in the range of the conversion of the measurement means from 0 to $15 \mathrm{Nm}$, the maximum value of the output value in the decimal code NMy corresponds to 5000 pulses (Figure 1), the difference of 57 denary pulses will match the decimal value of the torque of $0,17 \mathrm{Nm}$. This difference may be taken into account when processing the measurement results by a modification to the specified value of the decimal base.

To represent the obtained accuracy characteristics in accordance with international standards of quality evaluation measurements ${ }^{4,5}$ the method of recalculation of the additive and multiplicative errors in the measurement means in the instrumental component of the uncertainty is set out below. 


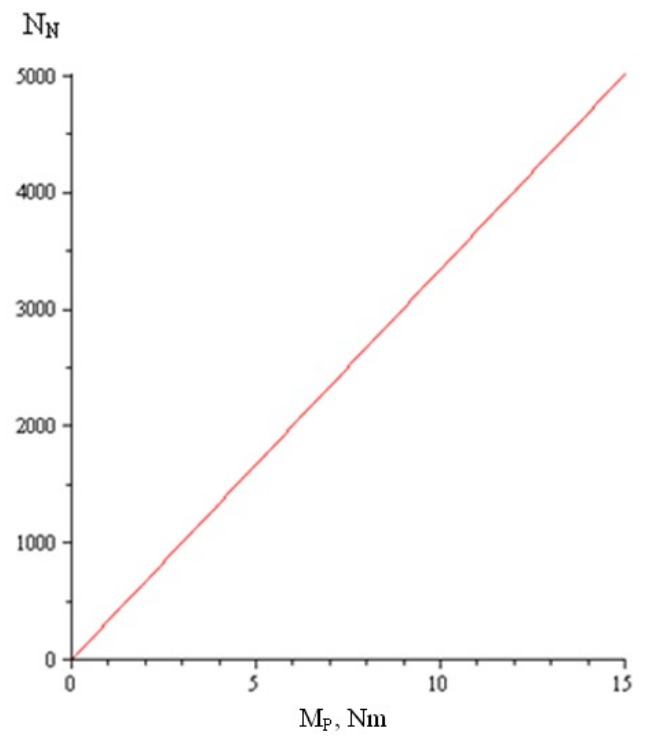

Figure 3. Description of change in the nominal function of the torque MM.

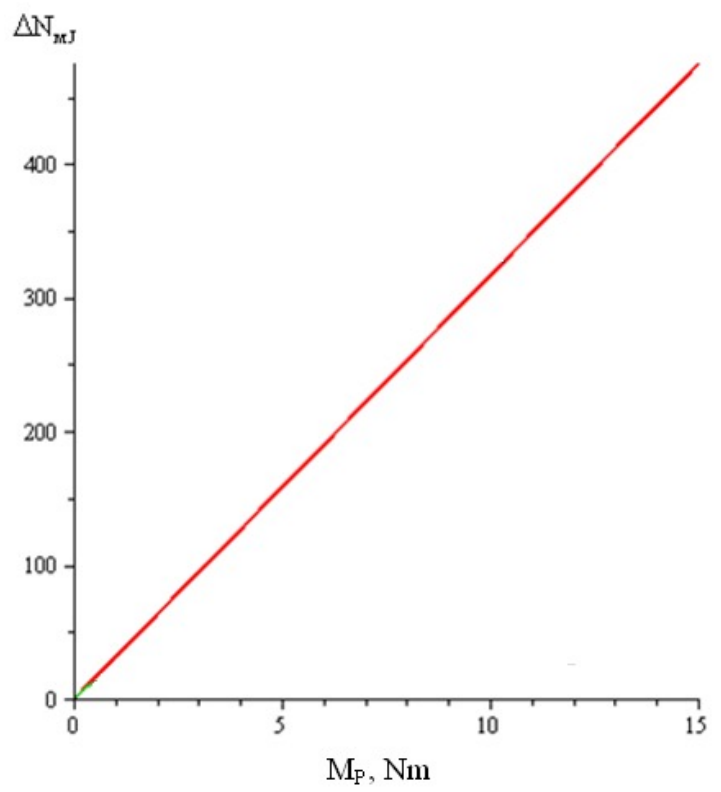

Figure 4. Description of change in the absolute multiplicative error of the torque MM under the conditions of deviation from the impact value on $\Delta \mathrm{J}$. 


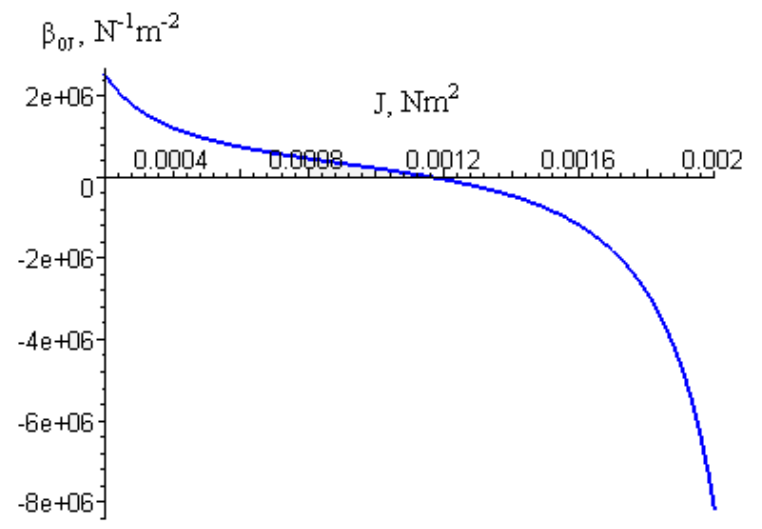

Figure 5. The coefficient affecting the impact value $\mathrm{J}$ on the output value.

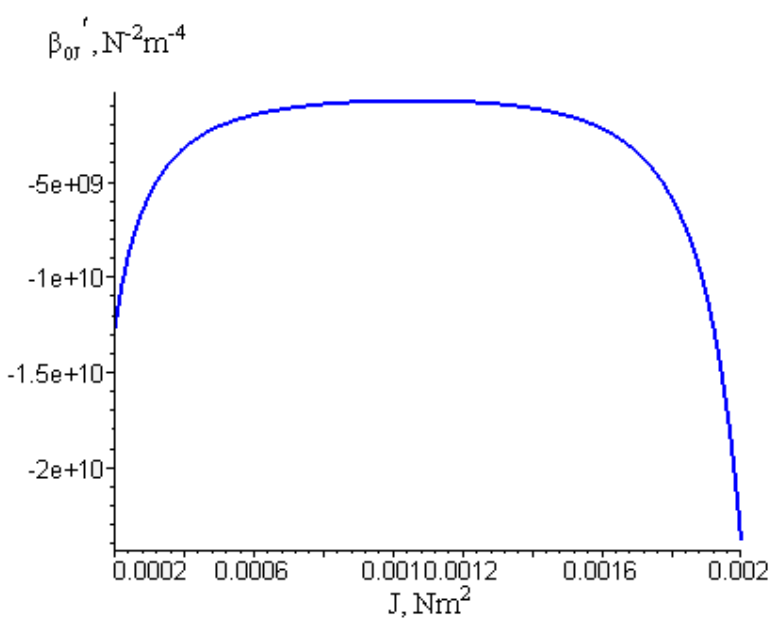

Figure 6 . The speed of change of the impact coefficient of the impact value $J$ on the output value.

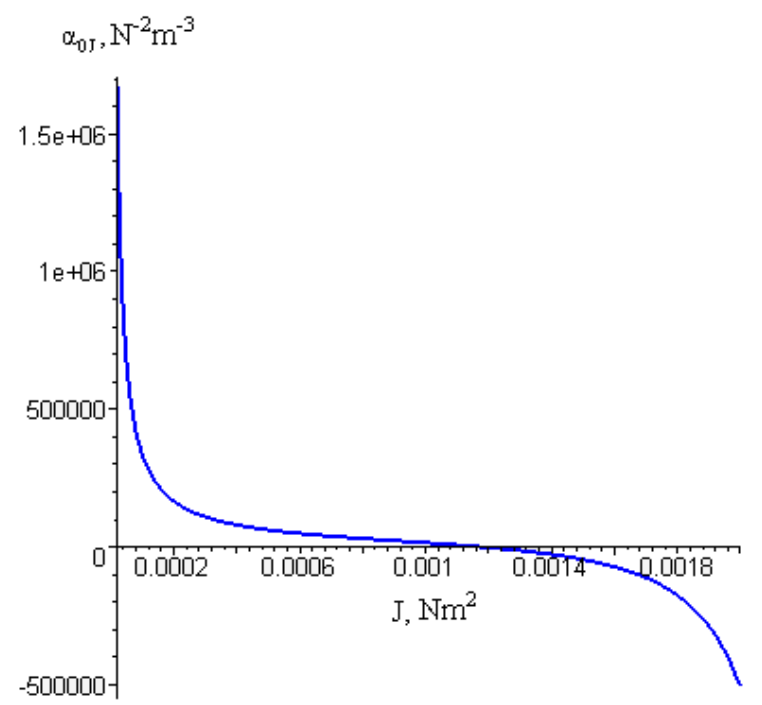

Figure 7. Characteristics of the change in the coefficient of the cumulative impact of the informative parameter and the impact value $\mathrm{J}$ on the value $\Delta \mathrm{J}$. 


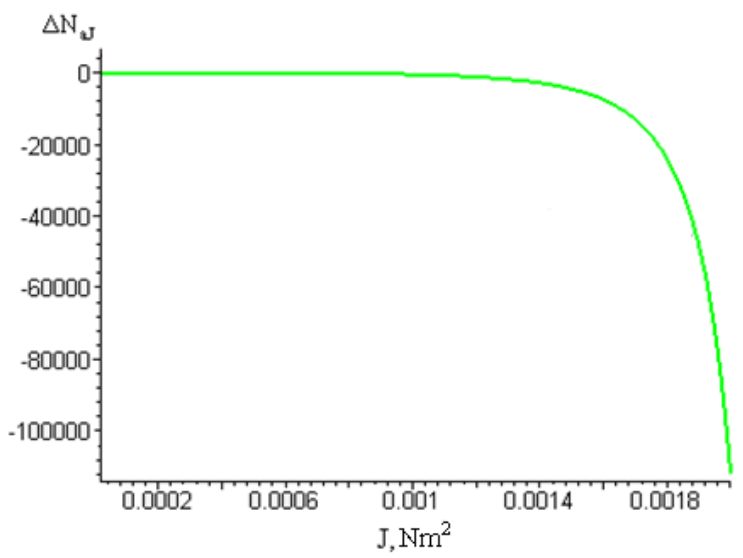

Figure 8 . The boundary of the change in the absolute additive error of the torque MM under the conditions of the deviation of the impact value on $\Delta \mathrm{J}$.

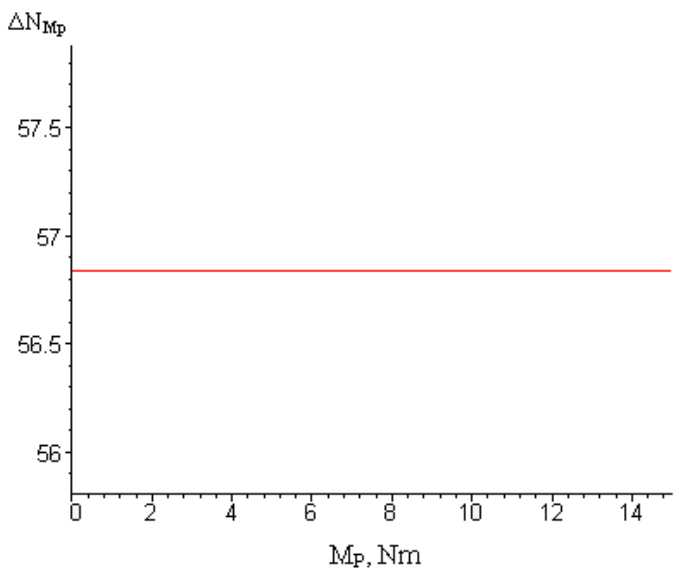

Figure 9. The difference between theoretical characteristics and the characteristics of the change in the nominal function of conversion.

\section{THE METHODOLOGY OF RECALCULATING THE COMPONENTS OF THE ADDITIVE AND MULTIPLICATIVE ERRORS OF THE MEASUREMENT MEANS IN THE INSTRUMENTAL COMPONENT OF UNCERTAINTY}

When using the above proposed methods to obtain metrological models for additive and multiplicative errors there is an issue to be considered of how to recalculate the components of such errors in the instrumental component of uncertainty, in order to represent the characteristics relating to the precision of measuring instruments, in accordance with international standards for evaluating the quality of measurements - the concept of uncertainty.

As a result of applying the model equation of the conversion of the measurement means to the Taylor series, we may obtain the additive $\Delta N_{a}$ and multiplicative $\Delta N_{m}$ components of error in the measurement means, which may in general be described by the expressions:

$$
\begin{gathered}
\Delta \mathrm{N}_{\mathrm{a}}=\frac{\partial \mathrm{N}}{\partial \eta}\left(\eta-\eta_{0}\right)+\frac{\partial^{2} \mathrm{~N}}{2 \partial \eta^{2}}\left(\eta-\eta_{0}\right)^{2}=\frac{\partial \mathrm{N}}{\partial \eta} \Delta \eta+\frac{\partial^{2} \mathrm{~N}}{2 \partial \eta^{2}} \Delta \eta^{2} ; \\
\Delta \mathrm{N}_{\mathrm{m}}=\frac{\partial^{2} \mathrm{~N}}{\partial \mathrm{x} \partial \eta}\left(\mathrm{x}-\mathrm{x}_{0}\right)\left(\eta-\eta_{0}\right)=\frac{\partial^{2} \mathrm{~N}}{\partial \mathrm{x} \partial \eta} \Delta \mathrm{x} \Delta \eta,
\end{gathered}
$$


where $\mathrm{N}$ is the output value of the measurement means $(\mathrm{MM})$; $\mathrm{x}$ is the measured input value; $\mathrm{x} 0$ is the nominal value of the input value (the value that under normal conditions meets the requirements for calibration of the MM); $\eta$ is the impact value; and $\eta 0$ is the nominal value of the impact value.

In order to recalculate the additive and multiplicative components of the error of the measurement means in the instrumental component of uncertainty necessary to determine the uncertainty of the measured input value $\mathrm{u}(\Delta \mathrm{x})$ and the impact value $\mathrm{u}(\Delta \eta)$ for the upper and lower boundaries $\left(\left[\mathrm{x}-; \mathrm{x}^{+}\right] \mathrm{i}[\eta-; \eta+]\right)$, having assumed a possible interpretation of the law, we may assess the distribution of error within the limits.

If nothing is known about the interpretation of the law of the distribution of the error within the limits, in accordance with international recommendations on the evaluation of measurement uncertainty, we should assume that there is equal probability that such an error may have any value with the accepted range, and hence we may adopt an even probability distribution. If the form of the distribution law of error within the boundaries of the studied values is known, then the uncertainty may be determined by taking into account the form of the distribution law based on the known formulae presented in ${ }^{9-14}$.

We may now consider the case where information about the nature of the distribution is absent, and in this case we should initially determine the uncertainty of the input and output values in accordance with the formulae:

$$
\mathrm{u}(\Delta \mathrm{x})=\Delta \mathrm{x} / \sqrt{12} ; \quad \mathrm{u}(\Delta \eta)=\Delta \eta / \sqrt{12} .
$$

We may then perform the recalculation of the additive and multiplicative components of the error in the measurement means in the instrumental component of uncertainty according to the formula

$$
\begin{aligned}
& \mathrm{u}_{\text {Binst }}^{2}=\left(\frac{\partial \mathrm{N}}{\partial \eta}\right)^{2} \mathrm{u}^{2}(\Delta \eta)+\left(\frac{\partial^{2} \mathrm{~N}}{2 \partial \eta^{2}}\right)^{2}(2 \Delta \eta \mathrm{u}(\Delta \eta))^{2}+\left(\frac{\partial^{2} \mathrm{~N}}{\partial \mathrm{x} \partial \eta}\right)^{2} \mathrm{u}^{2}(\Delta \mathrm{x}) \mathrm{u}^{2}(\Delta \eta)= \\
&=\left[\left(\frac{\partial \mathrm{N}}{\partial \eta}\right)^{2}+\left(\frac{\partial^{2} \mathrm{~N}}{\partial \eta^{2}} \Delta \eta\right)^{2}\right] \frac{\Delta \eta^{2}}{12}+\left(\frac{\partial^{2} \mathrm{~N}}{12 \partial \mathrm{x} \partial \eta} \Delta \mathrm{x} \Delta \eta\right)^{2}
\end{aligned}
$$

Let us now introduce the following factors for the influence $\vec{\eta}$ of the impact values on the output parameter value $\mathrm{N}$ :

$$
\begin{aligned}
& \sum_{i=1}^{n} \frac{\partial N}{\partial \eta_{i}}=\sum_{i=1}^{n} \beta_{0 i}, \\
& \sum_{i=1}^{n} \frac{\partial^{2} N}{2 \partial \eta_{i}^{2}}=\sum_{i=1}^{n} \beta_{0 i}^{\prime}
\end{aligned}
$$

and the coefficient of the influence of the impact values on the nominal sensitivity of the measurement means

$$
\sum_{i=1}^{n} \frac{\partial^{2} N}{\partial x \partial \eta_{i}}=\sum_{i=1}^{n} \alpha_{0 i}
$$

The model equation that will determine the instrumental component of the variance at the impact values (more than one impact value) takes the form

$$
\mathrm{u}_{\text {Binst }}^{2}=\sum_{\mathrm{i}=1}^{\mathrm{n}} \beta_{0 \mathrm{i}}^{2} \mathrm{u}^{2}\left(\Delta \eta_{\mathrm{i}}\right)+4 \sum_{\mathrm{i}=1}^{\mathrm{n}} \beta_{0 \mathrm{i}}^{\prime 2} \Delta \eta_{\mathrm{i}}^{2} \mathrm{u}^{2}\left(\Delta \eta_{\mathrm{i}}\right)+\sum_{\mathrm{i}=1}^{\mathrm{n}} \alpha_{0 \mathrm{i}}^{2} \mathrm{u}^{2}(\Delta \mathrm{x}) \mathrm{u}^{2}\left(\Delta \eta_{\mathrm{i}}\right) \text {. }
$$

When we consider equation (12), the analytical expression (17) for $\mathrm{n}$ impact values will take the form 


$$
u_{\text {Binst }}^{2}=\frac{\sum_{i=1}^{n}\left(\beta_{0 i} \Delta \eta_{i}\right)^{2}}{12}+\frac{\sum_{i=1}^{n}\left(\beta_{0 i}^{\prime} \Delta \eta_{i}^{2}\right)^{2}}{3}+\frac{\sum_{i=1}^{n}\left(\alpha_{0 i} \Delta x \Delta \eta_{i}\right)^{2}}{12^{2}} .
$$

For a single impact value the expression (18) takes the form

$$
\mathrm{u}_{\text {Binst }}^{2}=\frac{\left(\beta_{0} \Delta \eta\right)^{2}}{12}+\frac{\left(\beta_{0}^{\prime} \Delta \eta^{2}\right)^{2}}{3}+\left(\frac{\alpha_{0} \Delta x \Delta \eta}{12}\right)^{2}
$$

Thus, the method for recalculating the additive and multiplicative components of the error in the measurement means is reduced to the determination of the measured and impact values based on the a priori information on uncertainty of type B and the calculation of the formula of the instrumental component of variance (17).

This proposed method for the recalculation of the component of the instrumental error of the torque measurement means $(8,9)$ in the instrumental component of uncertainty may now tested with practical calculations.

In as much as it has been established (Figure 9) that the difference between the theoretical equation of the conversion (1) of the torque MM and the obtained nominal function of the conversion (7) across the whole measurement range of the torque is $0,17 \mathrm{Nm}$. Then the standard uncertainty of type $\mathrm{B}$, that is introduced by the differences between the nominal function of the conversion and the model equation of the measurement may be determined by the expression (12) thus $\mathrm{u}(\Delta \mathrm{M})=0,17 / \sqrt{12}=0,05 \mathrm{Nm}$.

Uncertainty of type $\mathrm{B}$, that is introduced by the deviation by the moment of inertia of the rotor of the EM $\Delta J=J-J_{N}=10^{-5} \mathrm{Nm}^{2}$, as an impact value under the assumption of evenness in the distribution law, is $\mathrm{u}(\Delta \mathrm{J})=$ $10^{-5} / \sqrt{12}=2,89 \cdot 10^{-6} \mathrm{Nm}^{2}$. In order to recalculate the additive and multiplicative components obtained for the error in the torque $\mathrm{MM}$ in the instrumental component of $\mathrm{t}$ uncertainty in the measurement, let us introduce the obtained values of the uncertainties $u(\Delta M)$ and $u(\Delta J)$, and maximum values of influence factors (4) - (6) at nominal parameters of the impact values shown in Figure 5 - Figure 7 to the analytical expression (17). The result is the value of the instrumental component of the variance in the torque measurement means, shown by the expression:

$$
\begin{gathered}
u_{\text {Binst }}^{2}(\Delta M, \Delta J)=\beta_{0 J}^{2} u^{2}(\Delta J)+4 \beta_{0 J}^{\prime 2} \Delta J^{2} u^{2}(\Delta J)+\alpha_{0 J}^{2} u^{2}(\Delta M) u^{2}(\Delta J)= \\
=\left(-8 \cdot 10^{6} N^{-1} m^{-2}\right)^{2}\left(2,89 \cdot 10^{-6} N m^{2}\right)^{2}+ \\
+4\left(-2,5 \cdot 10^{10} N^{-2} m^{-4}\right)^{2}\left(0,5 N m^{2}\right)^{2}\left(2,89 \cdot 10^{-6} N m^{2}\right)^{2}+ \\
+\left(1,65 \cdot 10^{6} \mathrm{~N}^{-2} \mathrm{~m}^{-3}\right)^{2}(0,05 \mathrm{Nm})^{2}\left(2,89 \cdot 10^{-6} \mathrm{Nm}^{2}\right)^{2}=536,68 .
\end{gathered}
$$

Taking the square root of the calculated value of the variance (20), we obtain an instrumental component of uncertainty that is 23.17 of the denary pulses of the output signal of the torque measurement means within the range of measurement from 0 to $15 \mathrm{Nm}$ at a maximum value of decimal pulses at the upper boundary of measurements at 5,000 (Figure 1). Having recalculated the obtained value of uncertainty for the denary pulses into an absolute value of the measured value $(15 \mathrm{Nm} * 23,17 / 5000=0,07 \mathrm{Nm})$, we obtain the value of instrumental component of uncertainty, which is $0,07 \mathrm{Nm}$ under the conditions where the deviation of the moment of inertia of the rotor of the electric motor from its nominal value by $10^{-5} \mathrm{Nm}^{2}$.

Thus, as a result of our study, we have shown that the instrumental component of uncertainty of the torque measurement means is $0.07 \mathrm{Nm}$ within a measurement from 0 to $15 \mathrm{Nm}$ with an acceptable deviation of the impact value (moment of inertia) of its nominal value by $10^{-5} \mathrm{Nm}^{2}$. 


\section{CONCLUSIONS}

Thus, the resulting mathematical tools and characteristics of change of the basic static metrological MM for torque give us the opportunity to identify the causes of increase in error in the measurement of torque in electric motors, to explore how to diminish or eliminate them, and also to synthesise torque MM with standardised metrological characteristics. The technique of converting additive and multiplicative components of error in the means measurement in the instrumental component of uncertainty enables us to present research results in the accuracy of measurement means in accordance with international standards and ensure the uniformity of measurements. This technique has been tested during research in the characteristics in the accuracy of the measurement of the torque electric motors.

\section{REFERENCES}

[1] ISO 9000:2005, [Quality management systems-Fundamentals and vocabulary], Geneva, Switzerland, ISO, 3031 (2005).

[2] ISO 9001:2008, [Quality management systems - Requirements], Geneva, Switzerland, ISO, 27 -28 (2008).

[3] ISO/TR 10017:2003, [Guidance on statistical techniques for ISO 9001:2000], Geneva, Switzerland, ISO, 26-27 (2003).

[4] ISO 5725-1:1994/Cor 1:1998, [Accuracy (trueness and precision) of measurement methods and results - Part 1: General principles and definitions], Geneva, Switzerland, ISO, (1998).

[5] ISO/IEC 17025:2005, [General requirements for the competence of testing and calibration laboratories], Geneva, Switzerland, ISO, 28-29 (2005).

[6] Vasilevskyi O. M., "Advanced mathematical model of measuring the starting torque motors", Tekhnichna elektrodinamika, Vol. 6, 76-81 (2013).

[7] Subrahmanyan V., [Electric Drives], McGraw-Hill, USA, 715-730 (1996).

[8] Vasilevskyi O. M., "Calibration method to assess the accuracy of measurement devices using the theory of uncertainty", International Journal of Metrology and Quality Engineering, 403-407 (2014).

[9] Evaluation of measurement data. [Guide to the expression of uncertainty in measurement, JCGM 100], GUM 1995 with minor corrections, 1 st ed. (2008).

[10] Vasilevskyi, O. M. "A frequency method for dynamic uncertainty evaluation of measurement during modes of dynamic operation", International Journal of Metrology and Quality Engineering 6.2, 202 -208 (2015).

[11] Romanyuk S. O., Pavlov S. V., Melnyk O. V., "New method to control color intensity for antialiasing", International "Siberian Conference Control and Communications (SIBCON)", (2015).

[12] Golijanek-Jędrzejczyk A., "Combined standard uncertainty estimation of loop impedance measurement determined by the shift method", Przeglad Elektrotechniczny, 4, 227-228 (2013).

[13] Miaskowski A., Cięszczyk S., "Two-step inverse problem algorithm for ground penetrating radar technique", Przeglad Elektrotechniczny, 12b, 22-23 (2011).

[14] Sawicki D., Kotyra A., "Comparision of selected flame area detection methods in vision diagnostic system", IAPGOS, 4, 14-17 (2013). 